\title{
Direito à Cidade e esfera pública: entre a participação política e a renovação jurídico-urbanística
}

\author{
The Right to the City and the public sphere: between political \\ participation and the renewal of the legal urbanistic order
}

Arthur Hirata Prist [I] Maria Paula Dallari Bucci [II]

\section{Resumo}

Este artigo propõe uma análise dos aspectos políticos e jurídicos do Direito à Cidade sob a perspectiva do conceito de esfera pública. O Direito à Cidade é interpretado como um elo dinâmico entre a mobilização política, a democratização das relações sociais e do aparato institucional do Estado e a garantia de melhores condições materiais de existência no espaço urbano. A partir da revisão bibliográfica sobre o tema das lutas sociais urbanas no Brasil e na cidade de São Paulo, pretende-se demonstrar que o Direito à Cidade é exercido pela população a partir dos embates na esfera pública responsáveis por impulsionar a renovação da ordem jurídica e atribuir novos sentidos ao Direito existente.

Palavras-chave: direito à cidade; esfera pública; participação política; função social da propriedade e da cidade; movimentos sociais.

\begin{abstract}
This article proposes an analysis of the political and legal aspects of the Right to the City from the perspective of the concept of public sphere. The Right to the City is interpreted as a dynamic link between political mobilization, democratization of social relations and of the State's institutional apparatus, and the guarantee of better material conditions of existence in the urban space. Based on a bibliographical research about the theme of urban social struggles in Brazil and in the city of São Paulo, the article intends to demonstrate that the Right to the City is exercised by the population through clashes in the public sphere, which are responsible for stimulating the renewal of the legal order and for attributing new meanings to the existing Law.
\end{abstract}

Keywords: right to the city; public sphere; political participation; social function of the property and of the city; social movements. 


\section{Introdução}

A pluralidade de apropriações do conceito de Direito à Cidade realizadas ao longo da história, desde sua formulação inicial por Lefebvre (2008), em 1968, torna bastante complexa e de certa forma despropositada a tarefa de delimitar uma definição única para o conceito. Fato é que o Direito à Cidade se apresenta como um "denominador comum da luta social" (Tavolari, 2016), tendo sido capaz de englobar tanto uma crítica à reificação da vida cotidiana em razão da submissão do espaço e da vida urbana à lógica mercantilista e ao valor de troca, quanto demandas localizadas de acesso a condições mínimas de usufruto dos recursos que a cidade provê.

Conceber o Direito à Cidade em sua polissemia exige, também, compreender que o conceito não pode ser reduzido a uma categoria jurídica do modo como estas são tradicionalmente pensadas. Não obstante, é evidente que a emergência do conceito e as suas diversas apropriações pela academia e pelos movimentos sociais foram fundamentais para que fossem verificadas profundas modificações na consciência jurídica a partir da reflexão crítica sobre o papel do direito no processo de urbanização.

Nesse sentido, Fernandes (2005) defende a superação do paradigma jurídico-urbanístico hegemônico segundo o qual o espaço urbano é concebido a partir da perspectiva do lote privado e do direito individual de propriedade. Esse paradigma conceitual se vê progressivamente confrontado por outro, segundo o qual a ordem jurídico-urbanística há de se estabelecer sobre a base de dois princípios fundamentais: a função socioambiental da propriedade e da cidade e a gestão democrática da cidade. Uma análise atenta de cada um desses princípios, e especialmente da interação existente entre os dois, pode contribuir para uma compreensão propriamente jurídica do Direito à Cidade. Vejamos.

O princípio da função social da propriedade e da cidade diz respeito, grosso modo, à "funcionalização do solo urbano no sentido de a todos servir, de maneira equânime" (Alfonsin et al., 2017, p. 1225), e, portanto, está associado a uma forma de desenvolvimento do espaço urbano que vise a atender de maneira igualitária as demandas e necessidades coletivas e individuais. A regulação da propriedade é, assim, retirada do âmbito privado e individualista, para se tornar questão de direito público, atravessada por uma dimensão coletiva. A cidade, por sua vez, deixa de ser vista como a soma de propriedades individuais e passa a ser considerada como um todo orgânico e complexo, fruto do trabalho coletivo (Fernandes, 2005).

Pode-se dizer que o princípio da função social da propriedade e da cidade está associado a uma dimensão material do Direito à Cidade. Diz respeito, portanto, à regulação das relações socioeconômicas que moldam a produção do espaço urbano e à garantia dos direitos fundamentais relacionados ao uso e fruição da cidade. No entanto, tal princípio não possui conteúdo nem aplicação predeterminada, mas estes são produzidos historicamente a partir da deliberação pública e pelas exigências da sociedade, as quais são absorvidas e interpretadas pelas instituições jurídicas, de modo que esse princípio configura a "incorporação de um conflito político pelo direito" (Haddad, 2019, p. 227). Essa constatação já aponta para sua interligação com o princípio da gestão democrática. 
O princípio da gestão democrática da cidade, por sua vez, está associado a uma dimensão política do Direito à Cidade. Essa dimensão foi explorada por Gomes (2018), sendo definida como o direito da população de participar da elaboração e implementação da política urbana, o que demanda a existência de canais participativos (não necessariamente institucionais) capazes de captar os direitos e interesses que são reivindicados pelas lutas sociais. Essa dimensão política também foi explorada por Harvey (2014), que concebe o Direito à Cidade como o poder coletivo de manipular e coordenar o processo de urbanização. Segundo o autor, a garantia do Direito à Cidade está intimamente ligada ao exercício da soberania popular sobre a atividade estatal, bem como ao controle democrático sobre a produção e o uso do excedente de capital no processo de urbanização (ibid., pp. 61-62).

A diferenciação entre essas duas dimensões do Direito à Cidade, representadas pelos referidos princípios jurídicos, contudo, não deve apontar para algo diferente do que uma interligação constitutiva entre elas, no interior da qual a possibilidade de participação na formulação da política urbana contribui diretamente para promoção da função social da propriedade e da cidade, e vice-versa. Como já apontado, o princípio da função social da propriedade e da cidade tem seus contornos e formas de aplicação definidos principalmente a partir da interação entre o Estado e a sociedade, isto é, pela participação política.

Adota-se a hipótese de que o Direito à Cidade não comporta uma definição jurídica estática, mas que sua existência reside exatamente no campo de interação entre sua dimensão política e sua dimensão material, aqui exemplificadas pelos princípios da gestão democrática da cidade e da função social da propriedade e da cidade, respectivamente. Sua efetivação como um direito propriamente dito, portanto, seria verificada quando a participação política da sociedade resulta na renovação das instituições jurídicas no sentido da funcionalização e democratização do solo urbano. Em outras palavras, trata-se de conceber o Direito à Cidade como um elo dinâmico de influência recíproca entre a mobilização política, a democratização das relações sociais e do aparato institucional do Estado e a garantia de melhores condições materiais de existência no espaço urbano. 0 presente artigo seguirá essa orientação analítica.

Explorar essa hipótese exige, antes de tudo, uma compreensão adequada de como a interação entre Estado e sociedade efetivamente se realiza, razão pela qual se dará centralidade ao conceito de esfera pública. Após a explicitação desse referencial teórico, a investigação compreenderá duas etapas: análise das lutas pela Reforma Urbana pós-redemocratização do Estado Brasileiro, seguida de um estudo específico sobre a cidade de São Paulo em seu atual contexto. Buscará se demonstrar que a garantia do Direito à Cidade depende da participação política da sociedade e, por consequência, da construção de uma esfera pública democrática.

\section{Esfera pública e democratização do Estado}

O conceito de esfera pública ${ }^{1}$ refere-se aos fluxos comunicativos espontâneos que se articulam na sociedade acerca de questões de interesse comum e público, por meio dos quais 
são veiculados conteúdos, opiniões, valores, visões de mundo, afetando a tomada de decisão, a formação da vontade e a construção da identidade no plano individual e coletivo. A esfera pública é pensada como o espaço social no qual discursos são externalizados e deliberações são travadas por coletividades interessadas em determinada questão de interesse comum, tendo em vista, em última instância, a obtenção do assentimento público e a tratativa racional e argumentativa dos mais diversos problemas sociais (Habermas, 1997; Avritzer e Costa, 2004; Melo, 2015).

Compreendida como instância de mediação entre o Estado e a sociedade, a esfera pública é descrita como uma "caixa de ressonância", a partir da qual temas e questões advindos da sociedade civil, ao serem problematizados com a intensidade devida, sinalizam, para o Estado, a necessidade de intervenção pública, servindo, também, como contexto de legitimação da atividade estatal em geral (Machado, Melo e Silva, 2010). Para melhor explicitar essa interação, pode-se valer da diferenciação entre esferas públicas "formais" - espaços de deliberação e decisão institucionalizados, internos ao Estado - e "informais" - contextos de comunicação localizados no interior da sociedade civil.

As esferas públicas formais constituem o "centro" do sistema comunicativo e de tomada de decisão do Estado, composto pelos complexos institucionais da administração, pelos tribunais de justiça e pelos corpos deliberativos estatais, com destaque para o Poder Legislativo (Habermas, 1997, pp. 86-87). A tomada de decisão por parte desses órgãos, a despeito de suas particularidades, deve ser precedida por uma deliberação aberta, inclusiva e pautada por razões, a qual há de servir como contexto de legitimação da decisão proferida ou da política pública a ser implementada. Nesse contexto, tornam-se fundamentais procedimentos e estratégias de participação, diálogo, negociação e harmonização de interesses, tendo em vista a obtenção de consensos entre os grupos sociais envolvidos pela questão pública em pauta, muitas vezes portadores de interesses distintos e antagônicos. Cabe ao Direito institucionalizar procedimentos capazes de proporcionar a representação equânime dos múltiplos grupos concernidos pela questão objeto de deliberação, revestindo-se, assim, a tomada de decisão de legitimidade democrática (ibid., p. 105).

As esferas públicas informais, compreendidas como as redes de comunicação informal localizadas no interior da sociedade civil que contribuem para a formação da opinião e da vontade, por sua vez, constituem a periferia do sistema. Atuariam, nessa instância, associações da sociedade civil, sindicatos, movimentos sociais, instituições culturais e religiosas, mídia, etc. (ibid., pp. 87-88). Apresentando-se como fluxos espontâneos, diferenciados, e caracterizados pelas mais diversas formas de manifestação e enunciação, as ações comunicativas próprias da esfera pública informal não buscam necessariamente a obtenção de consensos entre grupos distintos, mas principalmente o debate contínuo e exaustivo sobre questões de interesse público a partir de diferentes pontos de vista e, para se utilizar uma expressão corrente, "lugares de fala".

A esfera pública informal é caracterizada pelo dissenso político, isto é, pelo embate entre perspectivas e posições subjetivas diversas, o que contribui para a reformulação de valores e práticas e para a promoção de grandes mudanças de paradigma no interior do processo 
histórico. Nela, os grupos sociais disputam por influência, visando à obtenção do assentimento público e, portanto, um contexto de "ressonância" para suas opiniões, convicções e projetos políticos (ibid., pp. 95-96).

A democratização do Estado está associada ao papel mais ou menos decisivo dos processos comunicativos informais e periféricos sobre o desenvolvimento, a atividade e a tomada de decisão do sistema político. Isso aponta para uma necessária porosidade do Estado em relação aos interesses e demandas externalizadas pelos grupos sociais em suas interações comunicativas e políticas no interior da esfera pública informal (ibid., pp. 88-89). Em outras palavras, as decisões vinculantes prolatadas pelo Estado carecem de uma legitimidade que só pode advir de um alinhamento em relação às expectativas e necessidades da população - as quais não são dadas a priori, mas formuladas coletivamente por meio da comunicação informal e da mobilização política, estando, por isso, em constante mutação.

Essa forma de circulação de poder partindo da periferia em direção ao centro do sistema político, todavia, não é a regra na grande maioria, se não na totalidade dos atuais Estados democráticos, cujo poder é fortemente centralizado e exercido de forma aparentemente autônoma, quando não em prol dos interesses de uma minoria restrita detentora de poder econômico. Verificou-se no curso da história, contudo, que em determinadas circunstâncias, a mobilização da esfera pública por parte de atores provenientes da sociedade civil foi capaz de inverter a circulação oficial de poder, de modo que contribuições advindas desses sujeitos foram incorporadas pelo sistema político e pela ordem jurídica. Esse feito depende da capacidade de grupos advindos da sociedade civil de detectar e interpretar problemas sociais, mobilizar-se coletivamente a ponto de influenciar a opinião pública e, consequentemente, pressionar o Estado a articular uma determinada forma de intervenção pública ou promover a renovação da ordem jurídica (ibid., pp. 90-91).

É importante ter em perspectiva, porém, que nem toda contribuição ou demanda articulada pela sociedade civil representa necessariamente um passo na direção da democratização das relações sociais. Isso, pois, uma determinada "opinião pública" sobre uma questão, na grande maioria dos casos, representa apenas um consenso parcial em relação à sociedade como um todo, proveniente de um contexto localizado ou de um conjunto de atores portadores de interesses específicos. A parcialidade de uma opinião pública, por si só, não retira sua legitimidade, dado o extremamente complexo e heterogêneo contexto das sociedades contemporâneas. No entanto, tal constatação deve nos alertar para o fato de que, em certos casos, por trás de uma suposta unanimidade, pode haver um processo de subordinação ou supressão de opiniões divergentes, resultante das assimetrias de poder existentes no corpo social.

A legitimidade da influência que certa opinião pública há de exercer sobre a atividade estatal, portanto, estaria associada ao grau de inclusão do debate público que a precedeu, o qual idealmente deveria envolver todos os potenciais concernidos pela questão em discussão (ibid., pp. 92-98). Dessa feita, opiniões públicas provenientes de espaços de deliberação excludentes, de enunciação restrita ou, se for o caso, inexistentes, teriam menor legitimidade para influenciar a tomada de decisão no âmbito do Estado. 
A "inviabilidade da esfera pública”, apontada por Arantes (2007, p. 21), corresponderia ao seu tratamento como "coisa privada e pessoal" (Maricato, 2015a, p. 78), característica de sociedades patrimonialistas e elitistas, nas quais os interesses de uma minoria são tradicionalmente revestidos de um teor universalista, enquanto os interesses e necessidades da maioria da população, carente de condições equânimes de representação e manifestação política, são categoricamente negligenciados. Torna-se central, portanto, a cada situação prática, "saber quem pode realmente participar da formação porosa da opinião pública" (Melo, 2015, p. 18).

Essa tarefa é crucial, tendo em vista que a esfera pública, nos mais diversos contextos, foi construída a partir de exclusões constitutivas, isto é, pela seletividade em relação aos atores capazes de participar e se fazer ouvir no contexto social e aos conteúdos e opiniões a serem tratados como "questões de interesse público" (Fraser, 1992; Perlatto, 2015). Não se concebe, portanto, a existência de uma esfera pública única e homogênea, mas uma interação complexa entre uma multiplicidade de "públicos", formados por sujeitos sociais diversos e por variadas formas de organização, solidariedade e manifestação (Avritzer e Costa, 2004).

Em síntese, pode-se conceber, por um lado, a existência de um grupo de "públicos" articulados em torno de uma esfera pública dominante, composta pelos principais atores hegemônicos revestidos de poder social e econômico, bem como pelos meios de comunicação de massa; e, por outro, uma pluralidade de esferas públicas subalternas, espaços de sociabilidade e arenas discursivas a partir dos quais diferentes grupos desfavorecidos estabelecem suas próprias visões de mundo, elaboram suas identidades e formulam suas necessidades e demandas. Tais esferas públicas se relacionam de modo complexo, sendo porosas e complementares umas às outras, ainda que diferenciadas entre si. A partir da interação, muitas vezes conflituosa e dissensual, entre "públicos" dominantes e "públicos" subalternos, discursos hegemônicos são contrapostos por manifestações e contradiscursos provenientes de coletividades tradicionalmente excluídas dos espaços tradicionais de deliberação e manifestação (Fraser, 1992; Perlatto, 2015).

Através da denúncia às exclusões constitutivas da esfera pública dominante, grupos marginalizados escancaram as contradições de uma estrutura social que distribui de maneira desigual a "capacidade de ser ouvido e ocupar os melhores lugares, de definir objetos de discussão e deliberar sobre estes" (Pallamin, 2015 , p. 23). Ao buscarem condições de "participação paritária na vida comum", essas coletividades "contribuem para a redefinição constante dos sentidos do bem-estar moral e dos contornos do que é público" (ibid., p. 87). Valendo-se dessa observação, a esfera pública deve ser compreendida como uma entidade em constante reconstrução, marcada pelo conflito de valores e interesses fortemente antagônicos e em certos casos inconciliáveis, os quais são objeto de contínuas deliberações tendo em vista o andamento de negociações práticas entre distintos grupos sociais (Melo, 2015, p. 22).

São nas diversas instâncias que compõem a esfera pública que tais arranjos complexos de diálogo, negociação, contestação e manifestação são articulados, sobrepondo-se e intercalando-se de acordo com as situações 
práticas, os objetivos da própria deliberação, os grupos concernidos e os interesses em jogo. Como resultado, são reformuladas as condições de legitimidade da atividade estatal e impulsionados processos de renovação da ordem jurídica. Sobre essa perspectiva, apoia-se a concepção do Estado Democrático de Direito como um projeto inacabado, falível e carente de revisão, constantemente reelaborado pela participação política, por meio da qual o sistema de direitos e a consciência jurídica são atualizados, reinterpretados e institucionalizados de maneira mais apropriada (Habermas, 1997, p. 118).

No atual contexto, esse impulso para a renovação da ordem jurídica e atualização do Estado de Direito depende especialmente da integração social, econômica e cultural dos grupos vulneráveis e historicamente oprimidos e de sua maior participação nos processos deliberativos de formação da opinião pública e de tomada de decisão no âmbito do Estado. No que concerne especificamente à dimensão urbanística do problema, trata-se de ampliar o poder de influência da grande massa destituída dos benefícios do desenvolvimento urbano - desapropriados, irregulares, sem-teto, habitantes de territórios precários e favelas - sobre a tomada de decisão acerca de questões que concernem a cidade como um todo: definição do orçamento; aplicação de investimentos públicos em moradia, mobilidade, saneamento; delimitação de prioridades; retenção da mais-valia urbana; controle da função social da propriedade, para citar apenas algumas.

\section{As lutas pela Reforma Urbana e a participação política}

Na esteira do processo de redemocratização, as lutas pela Reforma Urbana no Brasil resultaram na assimilação pelo Estado e pelo ordenamento jurídico de reivindicações promovidas pelas classes populares historicamente alocadas nas periferias urbanas (Rolnik, 2017, pp. 239-266). A mobilização conjunta desses atores e de outros setores da sociedade civil, articulados em redes e movimentos coletivos, como o Fórum Nacional pela Reforma Urbana (FNRU) e a Confederação Nacional das Associações de Moradores (Conam), foi responsável por tornar as alarmantes condições de vida na periferia uma questão de "interesse público".

A participação política desses atores coletivos foi fundamental para que uma seção específica sobre Política Urbana, fruto de uma Emenda Popular, fosse incluída à Constituição Federal de 1988, bem como para que, 13 anos depois, fosse aprovado o Estatuto da Cidade (lei n. 10.257/2001), que regulamentou o referido capítulo constitucional (Bonduki, 2017; Alfonsin et al., 2017). Esses dispositivos foram responsáveis por consolidar, na ordem jurídico-urbanística nacional, o referido novo paradigma conceitual sobre política urbana, pautado pela função social da propriedade e da cidade e pela participação política nos processos decisórios da política urbana, demandas antigas dos movimentos sociais (Fernandes, 2005). 
A agenda de ampliação da participação social na política urbana, defendida desde os anos 1980 por setores ligados à Reforma Urbana e aplicada de maneira dispersa nos contextos locais, foi deslocada para o centro da arena política durante os 13 anos de tramitação do projeto de lei que viria a ser aprovado sob o título de Estatuto da Cidade. A aprovação desse dispositivo, inclusive, só foi possível em razão da mobilização e da constante pressão política exercida pelos movimentos sociais, com destaque para o referido FNRU, que acompanharam de perto e contribuíram ativamente para a redação final do projeto de lei aprovado. Nesse período, deflagrou-se o intenso conflito de interesses entre setores sociais ligados à Reforma Urbana e setores conservadores ou ligados ao capital, que acusavam o Estatuto da Cidade de atentar contra os princípios da propriedade privada e da livre iniciativa (Avritzer, 2010; Gomes, 2018).

Com a aprovação do Estatuto da Cidade, os seguintes instrumentos participativos foram previstos com a intenção de promover a democratização da gestão urbana: conselhos de políticas públicas; conferências; orçamento participativo; referendo popular, plebiscito e iniciativa popular de projeto de lei; debates e audiências públicas (Avelino, 2016). O Estatuto da Cidade também prescreveu a obrigatoriedade da participação popular, da publicidade e da transparência no processo de elaboração dos planos diretores municipais, instrumento tornado obrigatório para os municípios com mais de 20.000 habitantes. Tal fato tornou a conjuntura política local crucial para a promoção da Reforma Urbana, uma vez que a garantia da função social da propriedade, através da aplicação dos instrumentos de caráter redistributivo instituídos pelo Estatuto da Cidade - por exemplo, as Zonas Especiais de Interesse Social (Zeis) -, ficou condicionada a sua previsão e regulamentação nos respectivos planos diretores municipais (Bonduki, 2017).

A agenda da participação social tomou novo fôlego com a eleição de Lula, candidato do Partido dos Trabalhadores (PT), à presidência em 2002. Após sua eleição, foram criados o Ministério das Cidades (2003) e o Conselho Nacional das Cidades (2004), cuja atividade foi estreitamente vinculada à Conferência Nacional das Cidades, bem como às conferências estaduais, regionais e municipais (Rolnik, 2009). Paralelamente, conselhos sobre diversos campos de políticas públicas urbanas, como habitação, saneamento e transporte, foram instituídos em diversos municípios (Avelino, 2016).

No entanto, com o passar dos anos, uma postura que era de confiança por parte dos movimentos sociais em relação aos espaços institucionais de participação progressivamente se tornou de questionamento acerca das possibilidades concretas de interferir na tomada de decisão acerca da política urbana. Ainda que a presença nesses espaços não tenha deixado de ser considerada essencial, atores ligados aos movimentos sociais passaram a afirmar a ausência de um espaço efetivo de deliberação no interior das instituições participativas (Pandolfi e Espírito Santo, 2014; Trindade, 2014). A ausência de instâncias de coordenação dos espaços participativos instaurados, resultando em isolamento, fragmentação e consequente ineficácia das deliberações travadas (Avelino, 2016), e o progressivo esvaziamento dos espaços participativos, tal qual o Conselho da Cidade, e sua cooptação por parte do Ministério das Cidades (Fernandes, 2013), são alguns dos motivos para tal. 
O afastamento posterior do PT da promoção de uma agenda radical de partilha de poder com a sociedade civil, a partir da entrega da direção do Ministério das Cidades ${ }^{2}$ para partidos conservadores (Rolnik, 2009) e do abandono de práticas de participação popular em programas mais recentes de financiamento do desenvolvimento urbano (Programa de Aceleração do Crescimento - PAC e Minha Casa Minha Vida - PMCMV) ou na realização das obras relacionadas aos megaeventos (Copa do Mundo de 2014 e Olimpíadas de 2016), são outros motivos para o mesmo quadro de desconfiança (Bonduki, 2017, p. 45; Rolnik, 2017, p. 249). Desprovidas de espaços de participação popular e sendo coordenadas de forma quase independente pelas diretrizes do mercado imobiliário, tais políticas impactaram negativamente as cidades em razão do estímulo à especulação fundiária e do consequente aumento do preço da terra, do reforço à segregação socioespacial e da realização de despejos e remoções forçadas (cf. Maricato, 2015b; Rolnik et al., 2015).

\section{A aproximação entre Estado e mercado na cidade São Paulo}

A crescente valorização da participação política da sociedade civil nas últimas décadas, se, por um lado, proporcionou a ampliação do controle democrático sobre a atividade estatal, por outro, estimulou também a aproximação entre Poder Público e mercado no âmbito da elaboração e efetivação da política urbana, no que foi chamado de "confluência perversa" (Trindade, 2014). Nesse contexto, entidades ligadas ao mercado "passam a assumir ou ingerir nas incumbências que deveriam estar a cargo do poder público" (Arantes, 2007, p. 21), mobilizando a noção de interesse público como forma de legitimar a apropriação do apareIho do Estado para a persecução de interesses privados ligados à acumulação do capital.

Tal aproximação entre Estado e mercado está associada ao que se convencionou chamar de empreendedorismo urbano, um produto da ideologia neoliberal definido como um comportamento de governança urbana no qual alianças entre poderes públicos, organizações da sociedade civil e interesses privados são mobilizadas para promover ou administrar o desenvolvimento das cidades (Harvey, 2014, pp. 186-192; Rolnik, 2017, p. 242). Nesse contexto, a esfera pública é mobilizada de modo a fabricar consensos sobre os benefícios da adoção de um viés empresarial para a gestão urbana, tendo em vista o "crescimento a qualquer custo" (Arantes, 2000; Vainer, 2000; Ferreira, 2005; Fix, 2007).

Nesse quadro, a cidade estrutura-se como uma "máquina de crescimento", cujo objetivo final é "aumentar o volume da renda agregada por meio da intensificação da utilização da terra" (Fix, 2007, p. 24), no interior da qual os promotores imobiliários se utilizam de um consistente aparato ideológico e discursivo e de sua influência sobre a esfera pública, quando não de subterfúgios no mínimo moralmente questionáveis - como os altos valores dispendidos em campanhas eleitorais (Rolnik, 2017, pp. 64-65) - para interferir no funcionamento do mercado e, em especial, na tomada de decisão sobre a aplicação de investimentos públicos, almejando a obtenção de rendas diferenciais ou monopolistas. 
Na cidade de São Paulo, essa situação se evidencia de maneira mais flagrante, a partir da gestão de Paulo Maluf na prefeitura (19921995). Foi a partir desse período, marcado pelo estabelecimento do consenso neoliberal na sociedade brasileira e pela inserção da cidade de São Paulo nos circuitos financeiros globalizados, que a "máquina de crescimento paulistana" se estruturou de maneira mais acentuada e ativa. Pode-se notar, desde então, a proliferação de discursos advindos de associações da sociedade civil que visam a orientar a aplicação dos investimentos públicos para regiões específicas (Frúgoli Jr., 2000).

O chamado "mito da cidade global", por exemplo, foi instrumentalizado por diversos atores - investidores imobiliários, empreiteiras, Poder Público, grande mídia -, de modo a se forjar um consenso sobre a irreversibilidade e os supostos benefícios da inserção econômica da cidade na rede mundial de fluxos financeiros, justificando a canalização de enormes somas em investimentos públicos para regiões já historicamente privilegiadas, a fim de adequá-las à recepção de empreendimentos imobiliários que viriam a receber as grandes corporações do setor "terciário avançado", a despeito das restrições orçamentárias e do crescente processo de favelização da cidade (Ferreira, 2005; Fix, 2007, 2009).

Nesse contexto, houve um boom de empreendimentos imobiliários de alto padrão e uma intensa "modernização" do chamado quadrante sudoeste da cidade, que contou com a reurbanização da região da avenida Faria Lima e a construção de uma paisagem espetacular de "cidade global" ao longo da marginal Pinheiros. Inúmeras obras viárias já vinham sendo implementadas na região e adjacências desde 1985, mobilizando uma parcela mais do que considerável do orçamento público, processo que se intensificou a partir da década de 1990. Citam-se os túneis sob o parque Ibirapuera e o rio Pinheiros, Boulevar JK I e II, o prolongamento da Faria Lima, a avenida ao longo do córrego Água Espraiada e, mais recentemente, a ponte Estaiada (Maricato, 2000, pp. 158-159; Fix, 2009; Rolnik, 2017, p. 63).

A realização desse "pacote" de obras viárias não pode ser atribuída apenas à necessidade de incremento da mobilidade. Representaram, também, "chamarizes" ao investimento privado, sendo muitas vezes respostas a demandas diretas dos promotores imobiliários. No caso da construção da avenida Água Espraiada (atualmente Jornalista Roberto Marinho), a gestão municipal chegou ao ponto de realizar a remoção forçada e, em alguns casos, violenta de mais de cinquenta mil pessoas alocadas em favelas na região, com o objetivo de "limpar" o território para a iniciativa privada e possibilitar a sua máxima rentabilidade e valorização imobiliária (Fix, 2007, 2009).

0 desenvolvimento do quadrante sudoeste foi impulsionado por duas Operações Urbanas (Água Espraiada e Nova Faria Lima), parceria público-privada por meio da qual o aprimoramento da infraestrutura urbana de determinado perímetro é custeado pelo Estado a partir da venda de potencial construtivo adicional para empreendimentos a serem levantados no próprio perímetro da operação, ou, em outras palavras, pela flexibilização das normas de uso do solo em determinada área "estratégica".

Propagandeadas como "fórmulas mágicas" para viabilizar intervenções urbanas em um contexto de restrição fiscal, as operações urbanas comprovaram-se verdadeiros mecanismos de apropriação privada de recursos 
públicos (Fix, 2004). Com sua aplicação sendo apenas viável em áreas de alto potencial de valorização imobiliária e sendo inicialmente obrigatório que os recursos obtidos fossem reinvestidos no próprio perímetro da operação, esses instrumentos drenaram grande parcela do orçamento público, promoveram um círculo de reinvestimento em áreas já privilegiadas e restringiram a capacidade de desenvolvimento de territórios carentes e precários, em uma clara inversão de prioridades da atividade urbanística estatal (Massonetto, 2003).

As inúmeras críticas dirigidas às Operações Urbanas por setores técnicos e acadêmicos levaram à reformulação de parte de seus elementos a partir da aprovação do Plano Diretor Estratégico de 2014. Foram estabelecidos, no PDE 2014: o perímetro expandido - de modo a possibilitar a aplicação dos recursos obtidos em um perímetro maior ao da Operação, evitando a concentração dos investimentos -; a vinculação de $25 \%$ da receita obtida para a aquisição e edificação de habitação social; e a composição de conselhos gestores das operações com representação paritária da sociedade civil e do Poder Público (Bonduki e Rossetto, 2018, pp. 237-244).

0 mesmo processo de aproximação entre o Estado e setores da sociedade civil ligados ao mercado se evidencia nas atuais discussões sobre a requalificação do Centro Histórico. A partir dos anos 1990, um conjunto de atores, articulados em torno da Associação Viva o Centro (AVC) - entidade composta pelos grandes proprietários imobiliários da região -, passou a propagandear a necessidade de requalificação da região central, diante de sua degradação (Frúgoli Jr., 2000; Arantes, 2007). A partir de então, uma série de propostas de requalificação do Centro Histórico foi formulada, centrada na atração de investidores privados para a região central a partir de parcerias público-privadas, visando à reformulação da infraestrutura urbana, como a Operação Urbana Centro (OUC), o Programa Ação Centro (ProCentro) e seu corolário, o Projeto Nova Luz.

No caso do Projeto Nova Luz - cuja implementação foi suspensa, mas ainda não completamente descartada -, foi proposta a implementação de uma segunda forma de parceria público-privada, a Concessão Urbanística, regulamentada em São Paulo pela lei n. 14.197/2009. A partir dessa figura, a execução de obras urbanísticas em determinado perímetro pode ser atribuída a uma empresa ou consórcio de empresas, por meio de licitação. Como contrapartida, a concessionária pode explorar comercialmente os imóveis e áreas públicas instalados no perímetro, bem como promover desapropriações, o que até então era competência privativa do Estado (Pallamin, 2015, p. 69).

Nesse contexto de aproximação entre Estado e mercado, qualquer projeto que vise à requalificação do Centro Histórico deve ser conduzido sob a condição de evitar que os interesses do mercado imobiliário se sobreponham aos da população atualmente residente na região, em grande parte proveniente de classes baixas. A representação paritária e determinante desses setores sociais na formulação e implementação desses projetos, a segurança contra despejos e processos induzidos de gentrificação e a ampliação da habitação popular nesse território devem encabeçar o rol de prioridades do Poder Público em todas as etapas dessa possível intervenção. 


\section{Embates na esfera pública paulistana e seu impacto sobre o Direito}

O fato de entes ligados ao mercado terem exercido forte influência sobre a opinião pública e a política urbana paulistana nos últimos anos não significa a ausência de conflito ou de contestação por parte de outros setores da sociedade civil. Atos de resistência à mercantilização da terra urbana fizeram com que a cidade de São Paulo se tornasse palco de intensa disputa e enfrentamento político por parte de grupos portadores de interesses inconciliáveis com aqueles do mercado. Os processos de elaboração dos Planos Diretores Estratégicos de 2002 e 2014, por exemplo, deflagraram a existência de uma multiplicidade de interesses e expectativas divergentes acerca do desenvolvimento da cidade de São Paulo.

O PDE de São Paulo de 2002, um dos primeiros a serem aprovados após o início da vigência do Estatuto da Cidade, foi precedido por um amplo processo participativo, composto por 26 audiências públicas e múltiplas reuniões específicas com atores sociais diversos. Dentre as mais de 230 organizações que participaram do processo, a negociação foi fundamentalmente influenciada pela participação de três organizações coletivas, a saber, a Frente pela Cidadania, que representava o setor imobiliário, liderado pela Secovi; a Frente Popular pelo Plano Diretor, composta por movimentos sociais de moradia, ONGs e urbanistas vinculados ao FNRU, cuja principal demanda era a regulamentação, a autoaplicabilidade e a ampliação em número das Zonas Especiais de Interesse Social (Zeis); e a Defenda São Paulo, que agregava associações de moradores de classe média e cuja preocupação residia na manutenção das regras de zoneamento até então vigentes, em especial no que concerne às áreas exclusivamente residenciais (Bonduki e Rossetto, 2018, pp. 193-202).

Enquanto 0 atendimento das demandas dos dois últimos grupos foi negociado sem grandes entraves, a pressão exercida pelo setor imobiliário, por meio da Frente pela Cidadania, tornou bastante complexa a aprovação do Plano Diretor. O setor imobiliário contou com sua influência na esfera pública, inclusive a partir de uma ampla campanha publicitária crítica ao projeto de lei apresentado, para fazer valer seus interesses, em especial no que tange à não limitação do direito de construir. Após uma ampla negociação, todavia, estabeleceu-se uma restrição aos interesses do setor imobiliário, em benefício da coletividade, fixando-se a tese de que o direito de construir não é decorrência direta do direito de propriedade, mas deve estar atrelado à estratégia de desenvolvimento urbano estabelecida pelo PDE. Estabeleceu-se, assim, a cobrança pelo Estado de uma outorga onerosa para aqueles que desejassem atingir o coeficiente de aproveitamento máximo (CAM) estabelecido pelo zoneamento.

Para a elaboração do PDE de 2014, não apenas se reproduziu o processo participativo efetivado em 2002, mas este foi substancialmente ampliado e aperfeiçoado. A preocupação com a divulgação, transparência, negociação e incorporação de propostas e demandas caracterizou profundamente os nove meses de tramitação do Projeto de Lei do Plano Diretor de 2014, de modo que o texto aprovado foi consideravelmente diverso, e muito mais abrangente, que o inicialmente apresentado. Nesse período, foram realizadas 65 audiências públicas, assim como foi 
promovida uma ampla divulgação através de múltiplos meios de comunicação, estimulando o engajamento e a participação da sociedade civil (ibid., pp. 203-213).

As três principais organizações coletivas que participaram da elaboração do PDE de 2002 estiveram presentes em 2014, mas uma nova gama de interlocutores também teve papel significativo nesse processo. O Movimento dos Trabalhadores Sem Teto - MTST teve protagonismo não só pela conquista de novas zeis em áreas recém-ocupadas pelos seus militantes, mas também em razão da intensa pressão exercida pela aprovação do Plano Diretor após ter atendidas suas demandas, inclusive a partir da instalação de um acampamento - com outros movimentos de moradia - em frente à Câmara Municipal nos 10 dias finais de discussão do projeto de lei. A participação de coletivos independentes, por sua vez, foi fundamental para que fossem incorporados, ao PDE de 2014, tópicos e questões relacionadas à alteração do modelo hegemônico de desenvolvimento da cidade, em especial no que tange à utilização do espaço público, à mobilidade ativa, à agricultura urbana e ao patrimônio cultural.

Conclui-se que, nos processos de elaboração dos Planos Diretores de São Paulo de 2002 e 2014, a existência de um amplo processo de negociação e participação política viabilizou que consensos fossem obtidos e cristalizados em um marco jurídico revestido de legitimidade democrática. No entanto, a disputa política pelo Direito à Cidade não se encerra no estabelecimento de um dispositivo jurídico estático. Pelo contrário, realiza-se a partir de uma luta constante pela efetividade e pela elaboração coletiva das condições de aplicação da lei, mediante a participação política contínua e dinâmica. Isso significa que a obtenção de um consenso na forma de lei é apenas um passo inicial no processo, que prossegue na esfera pública por meio da disputa pela efetividade e pela interpretação da lei. Essa etapa é marcada pelo dissenso, pelo confronto de opiniões divergentes, os quais contribuem para o desenvolvimento do direito no tempo. Para concluir essa seção, buscar-se-á demonstrar que os embates na esfera pública operam ressignificações nos princípios da função social da propriedade e da cidade, garantidos constitucionalmente e pelo Estatuto da Cidade, mas desprovidos de sentido e condições de aplicação predefinidas.

Atualmente, formas diversas de manifestação e reivindicação são articuladas na cidade de São Paulo por aqueles que entendem que os espaços institucionais de deliberação não são suficientes para absorver suas demandas ou possibilitem verdadeiras transformações na política urbana. Nesse contexto, formas de ação direta são realizadas especialmente através da mobilização social e da atividade coordenada, almejando trazer visibilidade a questões e pontos de vista muitas vezes negligenciados ou abertamente rechaçados pelos espaços tradicionais de deliberação e formação da opinião pública, historicamente monopolizados pelas classes dominantes.

Um exemplo importante dessa modalidade de atuação são as ocupações de imóveis ociosos, realizadas por grupos envolvidos na luta pela moradia, em especial na região central da cidade, compreendida como local próprio para a construção de moradia popular, diante da oferta de infraestrutura urbana completa e da proximidade com o mercado de trabalho. A partir das ocupações, os movimentos sociais de moradia atribuíram visibilidade a uma das principais contradições do desenvolvimento 
urbanístico paulistano (e brasileiro): o restrito acesso à terra, a concentração fundiária nas mãos de poucos e o caráter excludente do mercado habitacional, resultando em um profundo déficit habitacional, convivendo com a retenção especulativa de imóveis vazios e inutilizados por proprietários que visam a obter rendas futuras (Boulos, 2018).

Essa prática se tornou uma estratégia central e sistemática desses movimentos a partir de 1997, como forma de pressionar politicamente as autoridades competentes, trazer visibilidade à pauta da moradia digna e exigir que o Estado abra canais de diálogo e negociação (Trindade, 2014). Ao direcionarem suas ocupações para a região central da cidade, onde se concentra o maior número de imóveis ociosos, os movimentos por moradia digna tornaram-se importantes atores no debate sobre as políticas públicas para o Centro Histórico, bem como os principais opositores aos mencionados projetos de requalificação da região (ibid., p. 134).

As ocupações de imóveis ociosos inserem-se em uma posição bastante ambígua, tanto social quanto juridicamente. À primeira vista, configuram uma ruptura com a ordem jurídica, especialmente no que concerne aos direitos de propriedade, razão pela qual são fortemente criticadas por parte da opinião pública e suprimidas pelo Estado através de ações de reintegração de posse. As precárias condições de vida às quais os ocupantes são submetidos, colocando em risco sua saúde e segurança, geram, inclusive, divergências no interior dos movimentos sociais por moradia em relação à validade das ocupações como local de moradia provisória (ibid., pp. 156-158). Essa situação de insegurança foi deflagrada pelo incêndio e desmoronamento do edifício Wilton Paes de
Almeida em maio de 2018 e se apresenta como um dos pontos mais sensíveis de discussão sobre as ocupações de imóveis ociosos.

A ambiguidade reside, todavia, no fato de que as ocupações de imóveis ociosos, ao mesmo tempo que ferem a ordem jurídica estabelecida no que concerne aos direitos de propriedade, configuram, paralelamente, uma reivindicação pela efetividade da própria ordem jurídica em questão, que garante o direito à moradia digna e exige que a propriedade privada cumpra sua função social (ibid., pp. 183-184; Boulos, 2018). Essa exigência deve ser cumprida pelo Estado a partir da fiscalização do uso do solo e pela aplicação dos instrumentos de parcelamento, edificação e utilização compulsórios, do IPTU progressivo no tempo e da desapropriação de imóveis ociosos. ${ }^{3}$ Estabelecidos pelo Estatuto da Cidade, tais instrumentos ainda apresentam pouca efetividade no combate à retenção especulativa de imóveis subutilizados (cf. Bonduki e Rossetto, 2018, pp. 216-222).

Sob outro ângulo, a despeito das precárias condições de vida em seu interior, as ocupações são compreendidas por grande parte dos ocupantes como a única forma viável de obter uma moradia, ainda que provisória, tendo em vista as condições excludentes do mercado habitacional (Boulos, 2018). Isso torna imprescindível que se discuta sobre a responsabilidade do Estado em prover condições mínimas de segurança aos residentes de ocupações, a despeito do caráter irregular da posse.

Sem deixar de considerar seu caráter ambíguo, ao mesmo tempo legítimo e ilegítimo, é de se reconhecer que as ocupações se apresentam como uma reação coletiva a um desenvolvimento urbanístico excludente e à evidente falta de eficácia de direitos e instrumentos 
redistributivos previstos no ordenamento jurídico, em especial na Constituição Federal e no Estatuto da Cidade (ibid.). Mediante sua prática política, os movimentos sociais incitam um debate sobre o estatuto da propriedade individual como um direito irrestrito, apontando para a necessidade de instrumentos jurídicos efetivos que garantam que seja cumprida sua função social (Trindade, 2014, p. 164). Esse tensionamento do campo discursivo é, ainda que de maneira descontínua e imprevisível, assimilado pela consciência jurídica e pelas autoridades estatais e judiciais, de forma que 0 próprio conteúdo da função social da propriedade é progressivamente atualizado.

Outras coletividades, por sua vez, vêm contribuindo para a construção do sentido de um princípio cuja indeterminação é ainda mais profunda, qual seja, o princípio da função social da cidade. Trata-se dos "novos ativismos urbanos" (Frúgoli Jr., 2018), associações e grupos de pessoas, em sua maioria organizadas horizontal e informalmente, que pleiteiam reformulações de certos aspectos da vida cotidiana da cidade. A proliferação desses grupos se dá em um momento de maior complexidade e heterogeneidade da esfera pública paulistana, documentado por Caldeira (2012, 2014a, 2014b), e resultante, em especial, dos anos de crescimento econômico, da ligeira redução das desigualdades socioeconômicas e da inclusão das classes populares a partir do consumo na primeira década do século XXI (cf. Marques, 2014).

Segundo Valluchi (2017), os novos ativismos urbanos, em síntese, propagam movimentos de comunização (commoning), o ato ou prática de tornar-se um bem comum. Nas palavras de Harvey (2014, p. 145), a comunização é uma forma de relação entre um grupo social e um bem ou aspecto do ambiente, na qual sua utilização e apropriação se dão de maneira coletiva e não mercantilizada. Os bens e espaços públicos encontrados na cidade não são, portanto, necessariamente "comuns", mas assim se tornam quando as forças sociais se apropriam deles, tendo em vista um objetivo coletivo e o seu equânime usufruto pela população em geral. Tornar a cidade e os recursos que esta incorpora um bem comum, acessível e manuseável por todos, é o princípio que, à primeira vista, orienta a ação desses ativistas.

Uma parte desses grupos exige mudanças substanciais nas utilizações correntes dos espaços públicos urbanos (Frúgoli Jr., 2018). No centro e na periferia da cidade, são pleiteados e ao mesmo tempo postos em prática a transformação, pontual ou definitiva, de vias públicas em parques e espaços de lazer (Haddad, 2019); o uso do espaço público para a cultura, a partir da realização de festas, festivais, exposições audiovisuais, performances artísticas e debates em áreas públicas (Almeida, 2013; Aderaldo, 2016; Verano, 2018); a gestão compartilhada dos espaços públicos e a promoção da agroecologia urbana e de hortas comunitárias (Machini, 2018).

A melhoria na oferta do transporte público, a contenção da escalada dos preços das tarifas e a sua primazia sobre o automóvel individual são também pleiteadas por coletivos como o Movimento Passe Livre - MPL, cujas manifestações foram o estopim para as chamadas Jornadas de Junho de 2013 (cf. Maricato et al., 2013). No núcleo de suas manifestações, está a concepção de que a livre circulação pela cidade é condição sine qua non para o seu usufruto coletivo pelos cidadãos. 
Unindo contestação e criatividade, os ativismos urbanos defendem a maximização da cidade como valor de uso, isto é, como palco de elaboração autônoma das necessidades coletivas e das formas sociais de satisfazê-las no espaço urbano (Lefebvre, 2008). Ao passo que rejeitam visões unilaterais do espaço público como mero local de passagem e de circulação de mercadorias e pessoas, enfatizam a possibilidade da permanência e simultaneidade; valorizam a cidade como local do encontro, do imprevisto, do jogo e da troca (ibid., p. 105).

Pleiteiam um espaço público marcado pela "indeterminação", de usos e de pessoas que por ele transitam, no qual o legítimo e o ilegítimo não são definidos a priori, mas construídos a partir da deliberação e da participação social. Tal espaço se associa à própria concepção da esfera pública democrática, aquela na qual, "dada a ausência de fundamentos, o significado e a unidade do social são negociados - ao mesmo tempo constituídos e colocados em risco" (Deutsche, 2018, pp. 120-121).

Tendo em vista esse objetivo, esses grupos não se limitam a exigir a possibilidade de acesso a um espaço público preexistente, mas buscam formas de exercer o direito de construir coletiva e progressivamente um espaço público imaginado e mais democrático, visto e apropriado na forma de um "comum". Tornam-se necessárias, portanto, ações de resistência coordenada aos processos de apropriação do espaço público pela lógica mercantilista e privatizante, que se multiplicam sob a égide do neoliberalismo (Harvey, 2014, pp. 164-169).

É notório que, em São Paulo, tal qual nas cidades brasileiras em geral, nunca existiu um espaço público apropriado na forma de um "comum". Em razão de um desenvolvimento urbanístico excludente e de outras condições materiais, políticas e sociais características de uma sociedade estratificada e desigual, a cidade como um todo e seus espaços públicos foram historicamente negados à grande maioria da população, expulsa para periferias cada vez mais distantes do centro dotado de infraestrutura, serviços e locais de cultura, lazer e consumo (cf. Caldeira, 2011; Rolnik, 2017). Mais recentemente, São Paulo vem se estruturando sob a forma de uma "cidade de muros", a partir da disseminação de espaços privados securitizados que negam frontalmente o espaço e a vida pública (Caldeira, 2011). Hoje esses enclaves fortificados tomam a forma de megaprojetos que mesclam funções residenciais, de consumo e negócios, constituindo "gigantescas máquinas antiurbanas" (Fix, 2009, p. 42). Sendo assim, não se pode compreender o espaço público como algo que foi perdido e precisa ser recuperado, mas sim como algo que precisa ser criado pela atividade política.

Esses movimentos e coletividades que atualmente reconfiguram a esfera pública paulistana, não se limitando àqueles que se autodenominam ativistas, mas envolvendo todos aqueles que articulam novas formas de se relacionar com a cidade, buscam a efetivação, ainda que sob nova roupagem, de princípios e direitos básicos: a possibilidade de circular, permanecer e intervir nos espaços urbanos; consumir os produtos disponíveis no mercado; expressar-se cultural e simbolicamente e formular suas próprias identidades; e, por fim, o direito ao reconhecimento moral e cívico daqueles que foram historicamente excluídos, invisibilizados e alvos das mais cruéis formas de violência (Caldeira, 2011, 2012, 2014a, 2014b; Pallamin, 2015). 
Essas atividades tornam a esfera pública paulistana extremamente pulsante e dissensual, de modo que novos sentidos e interpretações são atribuídos ao princípio da função social da cidade. A cidade deve ser constantemente transformada, de modo a possibilitar que suas múltiplas funções sejam exercidas de maneira equânime, tendo em vista a satisfação das diversas necessidades sociais das populações urbanas. Uma vez que novos sujeitos políticos demandam novas necessidades e atribuem novos usos aos espaços urbanos, o próprio conceito da função social da cidade expande-se, absorvendo essas atualizações advindas das práticas sociais. Como resultado da mobilização social, a cidade terá tantas funções quanto forem imaginadas para ela.

\section{Considerações finais}

Como se viu, desde o período de redemocratização do Estado brasileiro, a participação política foi determinante para a renovação do ordenamento jurídico-urbanístico em prol de um desenvolvimento urbano igualitário e democrático. No entanto, esse período contou também com evidentes descontinuidades - 0 esvaziamento e enfraquecimento dos espaços institucionais de participação política - e contradições - a penetração da ideologia neoliberal e das estratégias do empreendedorismo urbano no contexto brasileiro. Recentemente, novas formas de manifestação externas aos espaços institucionais de participação vêm ampliando o campo discursivo, expondo as contradições do processo de urbanização e postulando de maneira renovada transformações profundas nas atuais estruturas excludentes que conformam o espaço urbano e restringem suas funções e usos.

Buscou-se demonstrar que uma compreensão adequada do Direito à Cidade, ainda que sob uma perspectiva que considere seus aspectos jurídicos, exige um olhar para fora do Direito, em direção às práticas sociais e políticas. Existe uma contradição permanente e insolúvel entre o Direito existente, sua interpretação e formas de aplicação correntes e as práticas sociais, que continuamente articulam e demandam novos sentidos e um novo olhar sobre as instituições jurídicas, tendo em vista a democratização das relações sociais e o equânime usufruto de direitos e garantias constitucionais e infraconstitucionais. Como resultado dessa tensão, advinda da participação política, o Direito é progressivamente renovado e atualizado.

Como ideia geral, o Direito à Cidade traduz-se como o poder coletivo da população de modificar a forma pelo qual o processo de urbanização historicamente se realizou, resultando em exclusões, expropriações massivas e alienação. No curso da história, o Direito à Cidade apresentou-se como um contraponto a elementos estruturais da urbanização excludente que se verificou em escala global até os dias atuais, hoje impulsionados pela ideologia neoliberal e pela globalização: desenvolvimento territorial desigual, segregação socioespacial, mercantilização das relações sociais, privatização da existência, verticalização e rodoviarismo exacerbados, poluição e devastação ambiental, violência endêmica, negação de direitos sociais ou, o que em alguns casos é equivalente, negação dos próprios meios de vida. 
A partir desse conceito geral, o Direito à Cidade assume formas particulares nos contextos locais, fruto das múltiplas apropriações e interpretações que Ihe são dadas nos distintos contextos sociais, em especial pelos movimentos populares. A cada situação, categorias específicas são elaboradas, trazendo concretude ao conceito e direcionando a luta social para um sentido ou outro.

No caso brasileiro, o dinâmico processo de exercício do Direito à Cidade por parte da população encontra-se fortemente mediado pelos princípios da função social da propriedade e da cidade e da gestão democrática da cidade, os quais, em conjunto e em sua mútua implicação, são os fundamentos de um novo paradigma conceitual sobre a política urbana. Trata-se de categorias advindas das lutas sociais, formuladas e defendidas pelos próprios movimentos populares e posteriormente recepcionadas pelo Direito estatal e pela consciência jurídica. As atuais disputas pelo Direito à Cidade no Brasil podem, de maneira simplificada, ser compreendidas como reivindicações pela efetividade desses princípios e da ordem jurídico-urbanística que sobre eles se apoia.

Essas reivindicações são articuladas no interior da esfera pública a partir do embate de valores, visões de mundo e projetos políticos, responsável pela reformulação das condições de legitimidade da atividade estatal e pela atribuição de novos significados ao Direito existente. $O$ Direito à Cidade está associado, portanto, à construção de uma esfera pública, ou de esferas públicas ativas, heterogêneas, capazes de instaurar o conflito entre posições e valores compartilhados, estabelecendo o dissenso como instrumento para a renovação constante das práticas de reprodução social. Esse processo dar-se-á tão somente através da democratização horizontal e vertical da sociedade, isto é, a partir da redução das desigualdades internas ao corpo social e da crescente captação pelo Estado das demandas e expectativas elaboradas pela população.

[I] https://orcid.org/0000-0003-0785-9427

Pesquisador Autônomo. São Paulo, SP/Brasil

arthur.prist@hotmail.com

\section{[II] https://orcid.org/0000-0003-2862-8986}

Universidade de São Paulo, Faculdade de Direito, Departamento de Direito do Estado. São Paulo, SP/Brasil.

mariapaula@usp.br 


\section{Notas}

(1) O conceito de esfera pública foi inicialmente formulado por Jürgen Habermas em sua obra Mudança estrutural da esfera pública: Investigações sobre uma categoria da sociedade burguesa (2014), publicado originalmente em 1962. Posteriormente, o conceito foi recepcionado por diversos autores, que apresentaram uma posição crítica em relação à abordagem de Habermas, o que levou a uma progressiva renovação do conceito (cf. Avritzer e Costa, 2004). Já, em 1992, em sua obra Direito e democracia: entre facticidade e validade (1997), Habermas apresentou uma versão bastante modificada do conceito, atrelando-o à sua teoria da ação comunicativa e do procedimentalismo democrático. Esse artigo se baseia nesta última versão do conceito delineada por Habermas, bem como nas recepções críticas realizadas por outros autores.

(2) O Ministério das Cidades foi posteriormente extinto, no primeiro ano do Governo de Jair Bolsonaro, e com o também extinto Ministério da Integração Nacional, passou a constituir o Ministério do Desenvolvimento Regional.

(3) O parcelamento, edificação e utilização compulsórios, o Imposto sobre Propriedade Predial e Territorial Urbana (IPTU) progressivo no tempo e a desapropriação de imóveis ociosos foram previstos pelo Estatuto da Cidade, em suas seções de II a IV, como instrumentos a serem aplicados sequencialmente. Constatada a existência de solo urbano não edificado, subutilizado ou não utilizado, devem ser fixados a obrigação e o prazo para seu parcelamento, edificação ou utilização compulsória. Descumprida essa obrigação pelo proprietário no prazo fixado, o Município deve aplicar o IPTU progressivo no tempo, a partir da majoração da alíquota pelo prazo de cinco anos consecutivos. Por fim, decorridos os cinco anos de aplicação do IPTU progressivo no tempo, sem o cumprimento da obrigação pelo proprietário, o Município deve proceder à desapropriação do imóvel subutilizado. A aplicação desses instrumentos, todavia, fica a cargo do Município e depende da previsão e regulamentação nos planos diretores municipais, o que torna fundamental a mobilização política local em prol de sua efetividade.

\section{Referências}

ADERALDO, G. A. (2016). “Entre imagens e imaginários: estética e política nas intervenções visuais/ audiovisuais de coletivos culturais paulistanos". In: KOWARICK, L.; FRÚGOLI JR., H. (orgs.). Pluralidade urbana em São Paulo: vulnerabilidade, marginalidade, ativismos. São Paulo, Editora 34 e Fapesp.

ALFONSIN, B. M. et al. (2017). Das ruas de Paris a Quito: o direito à cidade na Nova Agenda Urbana HABITAT III. Revista de Direito da Cidade. Rio de Janeiro, v. 9, n. 3, pp. 1214-1246.

ALMEIDA, R. S. (2013). Juventude, direito à cidade e cidadania cultural na periferia de São Paulo. Revista do Instituto de Estudos Brasileiros. São Paulo, n. 56, pp. 151-172.

ARANTES, O. (2000). "Uma estratégia fatal: a cultura nas novas gestões urbanas". In: ARANTES, O.; VAINER, C.; MARICATO, E. (orgs.). A cidade do pensamento único - desmanchando consensos. Petrópolis, Vozes. 
ARANTES, P. (2007). Interesse público, poderes privados e práticas discursivas na política de renovação do Centro de São Paulo. São Paulo, Instituto Polis.

AVELINO, D. P. (2016). “Cidade e cidadania: considerações sobre a gestão democrática na política urbana brasileira". In: COSTA, M. A. (org.). O Estatuto da Cidade e a Habitat III: um balanço de quinze anos de política urbana no Brasil e a nova agenda urbana. Brasília, Ipea.

AVRITZER, L. (2010). O Estatuto da Cidade e a democratização das políticas urbanas no Brasil. Revista Crítica de Ciências Sociais [on-line], v. 91, pp. 205-221. Disponível em: https://journals. openedition.org/rccs/4491. Acesso em: 21 jan 2021.

AVRITZER, L.; COSTA, S. (2004). Teoria crítica, democracia e esfera pública: concepções e usos na América Latina. Dados - Revista de Ciências Sociais. Rio de Janeiro, v. 47, n. 4, pp. 703-728.

BONDUKI, N. (2017). Política urbana e a reforma do Estado: da redemocratização aos novos desafios do século XXI. Revista Simetria. São Paulo, v. 1, n. 3, pp. 41-52.

BONDUKI, N.; ROSSETTO, R. (2018). “A reforma urbana no Plano Diretor Estratégico de São Paulo de 2002 a 2014". In: BONDUKI, N. (org.). A luta pela reforma urbana no Brasil: do seminário de Habitação e Reforma Urbana ao Plano Diretor de São Paulo. São Paulo, Instituto Casa da Cidade.

BOULOS, G. (2018). Por que ocupamos? Uma introdução à luta dos sem-teto. São Paulo, Autonomia Literária.

CALDEIRA, T. P. do R. (2011). Cidade de Muros. São Paulo, Editora 34 e Edusp.

(2012). Inscrição e circulação: novas visibilidades e configurações do espaço público em São Paulo. Novos Estudos - Cebrap [on-line], n. 94, pp. 31-67. Disponível em: https://www.scielo.br/ pdf/nec/n94/n94a02.pdf. Acesso em: 21 jan 2021.

(2014a). Gênero continua a ser o campo de batalhas: juventude, produção cultural e a reinvenção do espaço público em São Paulo. Revista USP. São Paulo, n. 102, pp. 83-100.

(2014b). Qual a novidade dos rolezinhos? Espaço público, desigualdade e mudança em São Paulo. Novos Estudos - Cebrap [on-line], n. 98, pp. 13-20. Disponível em: https://www.scielo.br/ pdf/nec/n98/02.pdf. Acesso em: 21 jan 2021.

DEUTSCHE, R. (2018). Agorafobia. Arte e Ensaios - UFRJ. Rio de Janeiro, n. 36, pp. 116-173.

FERNANDES, E. (2005). Direito e gestão na construção da cidade democrática no Brasil. Oculum Ensaios. Campinas, n. 4, pp. 16-33.

(2013). Estatuto da Cidade, mais de 10 anos depois: razão de descrença, ou razão de otimismo? Revista UFMG. Belo Horizonte, v. 20, n. 1, pp. 212-233.

FERREIRA, J. S. W. (2005). O mito da cidade-global: o papel da ideologia na produção do espaço terciário em São Paulo. Revista do Programa de Pós-Graduação em Arquitetura e Urbanismo da FAU/USP. São Paulo, v. 16, pp. 26-48.

FIX, M. (2004). "A "fórmula mágica" da parceria público-privada: operações urbanas em São Paulo" In: SCHICCHI, M. C.; BENFATTI, D. (orgs.). Urbanismo: dossiê São Paulo - Rio de Janeiro. Campinas, PUCCamp/Prourb.

(2007). São Paulo cidade global: fundamentos financeiros de uma miragem. São Paulo, Boitempo. (2009). Uma ponte para a especulação: a arte da renda na montagem de uma "cidade global". Cadernos CRH. Salvador, v. 22, n. 55, pp. 41-64. 
FRASER, N. (1992). Rethinking the public sphere: a contribution to the critique of actually existing democracy. Social Text, n. 25/26, pp. 56-80.

FRÚGOLI JR., H. (2018). Ativismos urbanos em São Paulo. Caderno CRH. Salvador, v. 31, n. 82, pp. 75-86.

(2000). Centralidade em São Paulo: trajetórias, conflitos e negociações na metrópole. São Paulo, Editora da Universidade de São Paulo.

GOMES, A. M. I. dos S. (2018). O direito à cidade sob uma perspectiva jurídico-sociológica. Revista Direito GV [on-line], v. 14, n. 2, pp. 492-512. Disponível em: http://bibliotecadigital.fgv.br/ojs/ index.php/revdireitogv/article/view/77109/73915. Acesso em: 21 jan 2021.

HABERMAS, J. (1997). Direito e democracia: entre facticidade e validade, v. II. Rio de Janeiro, Tempo Brasileiro.

(2014). Mudança estrutural da esfera pública: investigações sobre uma categoria da sociedade burguesa. São Paulo, Ed. Unesp.

HADDAD, F. (2019). Função social das vias urbanas: uma análise à luz da teoria jurídica das políticas públicas. Dissertação de mestrado. São Paulo, Universidade de São Paulo.

HARVEY, D. (2014). Cidades rebeldes: do direito à cidade à revolução urbana. São Paulo, Martins Fontes.

LEFEBVRE, H. (2008). O direito à cidade. São Paulo, Centauro.

MACHADO, M. R. A.; MELO, R.; SILVA, F. G. (2010). A esfera pública e as proteções legais anti-racismo no Brasil. Cadernos de Filosofia Alemã. São Paulo, n. 16, pp. 95-116.

MACHINI, M. (2018). “Fluxos e sentidos da cidade-em-cultivo". In: MAGNANI, J. C.; SPAGGIARI, E. (orgs.). Lazer de perto e de dentro: uma abordagem antropológica. São Paulo, Ed. Sesc.

MARICATO, E. (2000). “As ideias fora do lugar e o lugar fora das ideias”. In: ARANTES, O.; VAINER, C.; MARICATO, E. A cidade do pensamento único - desmanchando consensos. Petrópolis, Vozes.

(2015a). “Globalização e política urbana na periferia do capitalismo". In: MARICATO, E. Para entender a crise urbana. São Paulo, Expressão Popular.

(2015b). "Cidades e luta de classes no Brasil”. In: MARICATO, E. Para entender a crise urbana. São Paulo, Expressão Popular.

MARICATO, E. et al. (2013). Cidades rebeldes: passe livre e as manifestações que tomaram as ruas do Brasil. São Paulo, Boitempo e Carta Maior.

MARQUES, E. (2014). A metrópole de São Paulo no início do século XXI. Revista USP. São Paulo, n. 102, pp. 23-32.

MASSONETTO, L. F. (2003). Operações Urbanas Consorciadas: a nova regulação urbana em questão. Revista da Procuradoria-Geral do Município de Porto Alegre. Porto Alegre, n. 17, pp. 101-118.

MELO, R. (2015). Repensando a esfera pública: esboço de uma teoria crítica da democracia. Lua Nova: Revista de Cultura e Política [on-line], v. 1, n. 94, pp. 11-39. Disponível em: https://www.scielo. br/pdf/In/n94/0102-6445-In-94-00011.pdf. Acesso em: 21 jan 2021.

PALLAMIN, V. (2015). Arte, cultura e cidade. São Paulo, Annablume. 
PANDOLFI, D.; ESPÍRITO SANTO, W. R. do (2014). "Movimentos sociais urbanos e esfera pública: questões para o debate". In: LOPES, J. S. L. e HEREDIA, M. A. de. (orgs.). Movimentos sociais e esfera pública: o mundo da participação: burocracias, confrontos, aprendizados inesperados. Rio de Janeiro, CBAE.

PERLATTO, F. (2015). Seletividade da esfera pública e esferas públicas subalternas: disputas e possibilidades na modernização brasileira. Revista de Sociologia e Política-UFPR. Curitiba, v. 23, n. 53, pp. 121-145.

ROLNIK, R. (2009). Democracia no fio da navalha: limites e possibilidades para a implementação de uma agenda de Reforma Urbana no Brasil. Revista Brasileira de Estudos Urbanos e Regionais [on-line], v. 11, n. 2, pp. 31-50. Disponível em: https://rbeur.anpur.org.br/rbeur/article/view/219/203. Acesso em: 21 jan 2021

(2017). Territórios em conflito: São Paulo: espaço, história e política. São Paulo, Três Estrelas.

ROLNIK, R. et al. (2015). O Programa Minha Casa Minha Vida nas regiões metropolitanas de São Paulo e Campinas: aspectos socioespaciais e segregação. Cadernos Metrópole. São Paulo, v. 17, n. 33, pp. 127-154.

TAVOLARI, B. (2016). Direito à cidade: uma trajetória conceitual. Novos Estudos - Cebrap [online], v. 35, n. 1, pp. 93-109. Disponível em: https://www.scielo.br/pdf/nec/v35n1/1980-5403-nec-35-01-93. pdf. Acesso em: 21 jan 2021,

TRINDADE, T. A. (2014). Ampliando o debate sobre a participação política e a construção democrática: o movimento de moradia e as ocupações de imóveis ociosos no centro da cidade de São Paulo. Tese de doutorado. Campinas, Universidade Estadual de Campinas.

VAINER, C. (2000). "Pátria, empresa e mercadoria". In: ARANTES, O.; VAINER, C.; MARICATO, E. A cidade do pensamento único - desmanchando consensos. Petrópolis, Vozes.

VALLUCHI, L. V. B. (2017). São Paulo, da cidade de muros à cidade ocupada: insurgências e contradições. In: XVII ENCONTRO NACIONAL DA ASSOCIAÇÃO NACIONAL DE PÓS-GRADUAÇÃO E PESQUISA EM PLANEJAMENTO URBANO E REGIONAL. Anais... São Paulo.

VERANO, P. N. (2018). Cidades temporárias: brechas e contrabrechas na cidade. Tese de doutorado. São Paulo, Universidade de São Paulo.

Texto recebido em 11/ago/2020

Texto aprovado em $7 /$ dez/2020 